\title{
Brook trout (Salvelinus fontinalis) extinction in small boreal lakes revealed by ephippia pigmentation: a preliminary analysis
}

\author{
Alexandre Bérubé Tellier, ${ }^{1 *}$ Paul E. Drevnick, ${ }^{2 \#}$ Andrea Bertolo ${ }^{1}$ \\ ${ }^{1}$ Département des Sciences de l'environnement, Université du Québec à Trois-Rivières, 3351 bd des Forges C.P.500, Trois-Rivières \\ G9A 5H7, Québec, Canada; ${ }^{2}$ Institut national de la recherche scientifique, Centre Eau Terre Environnement, Université du Québec - \\ 490 de la Couronne, Québec G1K 9A9, Canada \\ "Present address: University of Michigan, Biological Station, 440 Church St., Ann Arbor, MI 48109, USA \\ *Corresponding author: alexandre.berube.tellier@uqtr.ca
}

\begin{abstract}
Ephippium pigmentation is a plastic trait which can be related to a trade-off between visual predation pressure and better protection of cladoceran eggs against different types of stress. Experimental studies showed that planktivorous fish exert a greater predation pressure on individuals carrying darker ephippia, but little is known about the variation of ephippium pigmentation along gradients of fish predation pressure in natural conditions. For this study, our sampling design included four small boreal lakes with known fish assemblages. Two of the lakes have viable brook trout (Salvelinus fontinalis) populations, whereas the other two lakes experienced brook trout extinctions during the $20^{\text {th }}$ century. Cladoceran ephippia were extracted from sediment cores at layers corresponding to the documented post- extinction phase (1990's) and from an older layer (1950's) for which the brook trout population status is not known precisely. Our first objective was to determine whether brook trout extinction has a direct effect on both ephippium pigmentation and size. Our second objective was to give a preliminary assessment of the status of brook trout populations in the 1950's by comparing the variation in ephippia traits measured from this layer to those measured in the 1990's, for which the extinction patterns are well known. Cost-effective image analysis was used to assess variation in pigmentation levels in ephippia. This approach provided a proxy for the amount of melanin invested in each ephippium analysed. Our study clearly shows that ephippium pigmentation may represent a better indicator of the presence of fish predators than ephippium size, a trait that showed a less clear pattern of variation between lakes with and without fish. For the 1990's period, ephippia from fishless lakes were darker and showed a slight tendency to be larger than ephippia from lakes with brook trout. However, no clear differences in either ephippium size or pigmentation were observed between the 1990's and 1950's layers within each lake. This suggests that brook trout extinction already occurred before the 1950's, or that brook trout population abundance was already extremely low before the 1990's. Our preliminary study shows that ephippium pigmentation can be used as a tool to quickly assess present and past predation levels on zooplankton when only sediment samples are available.
\end{abstract}

Key words: Cladocerans; ephippia; extinction; pigmentation; predation; Salvelinus fontinalis.

Received: July 2016. Accepted: November 2016.

\section{INTRODUCTION}

It has been observed that ephippia pigmentation is a plastic trait (Gerrish and Cacéres, 2003; Hansson, 2004) which can be related to a trade-off between visual predation pressure (Mellors, 1975; Zaret and Kerfoot, 1975; Reinikainen, 2012) and better protection for eggs against different types of stress (Zaret, 1972; Hessen, 1996; Gerrish, 2001). Mellors (1975) documented that planktivorous fish put greater predation pressure on individuals carrying darker ephippia, but there is more to learn about ephippia pigmentation in different lake types, especially varying in predation degree. In this study, we used a set of model lakes with known typology (Plante, 1996b) to document ephippia pigmentation variation.

The establishment of La Mauricie National Park of Canada (LMNPC) in 1970 allowed the protection of 536.5 $\mathrm{km}^{2}$ of Canadian Shield of great ecological and cultural value. Despite the cessation of major human disturbance (e.g., logging and fishing), the extinction of populations of brook trout (Salvelinus fontinalis Mitchill, 1814) in small lakes observed during the first half of the $20^{\text {th }}$ century (see Bertolo et al., 2008), continued after the establishment of the park. Many factors might have caused these extinctions, including the introduction of non-native fishes and transient hypoxia/anoxia events due to beaver (Castor canadensis Kuhl, 1820) damming (Bertolo et al., 2008). The creation of LMNPC was in fact followed by a rise of the beaver population into its territory (Masson et al., 2001) due to the end of trapping activities (Plante, 1996a). Whereas the actual occurrence of most fish species, and especially the presence or absence of brook trout, is relatively well known for most lakes in the LMNPC, the picture is less clear for the period preceding 1970. The historical data referring to the period before the creation of the park, which were obtained from fishing 
clubs and other historical archives (Plante, 1996b), do not always provide accurate information about the status of the fish community or the timing of extinction events. Although the documented presence of viable brook trout populations in some lakes after the creation of LMNPC indicates that the species was also present before, identifying the exact moment of brook trout extinction events in other lakes remains a challenge. Here we propose to use a paleolimnological approach to help solve this issue.

Paleolimnological tools can be used to indirectly infer the presence of planktivorous fish (Jeppesen et al., 2002; Davidson et al., 2011) at the moment of park creation by providing estimates of key traits of the zooplankton community related to predation pressure. In particular, sediments accumulated at the bottom of lakes contain cladoceran ephippia, which can give an approximate portrait of the size structure of the cladoceran assemblage and allow us to infer about the levels of predation in which they were produced (Brooks and Dodson, 1965; Jeppesen et al., 2002). It has been observed that large cladocerans possess a wide range of phenotypic plasticity and genetic variation associated to body size, that are widely used as indicators of predation pressure from planktivorous fish (Jeppesen et al., 2002; Dzialowski et al., 2003). It has also been observed that more pigmented individuals are exposed to stronger predation pressure by visual predators (Zaret and Kerfoot, 1975). Daphnia carrying darker ephippia are known to suffer greater predation than specimens with less pigmented ephippia (Mellors, 1975). As a result, cladocerans tend to reduce the pigmentation of appendices and organs (Zaret, 1972) or to reduce the size of darker body parts in the presence of planktivorous fish (Reinikainen, 2012). A similar phenomenon is observable also for copepods, where the presence of carotenoids, while allowing a better protection against both UV radiation and parasites, makes them more conspicuous to predators (Hansson, 2004; van Der Veen, 2005). Therefore, in different species of both cladocerans and copepods it is possible to observe a trade-off between resistance to stress factors and vulnerability to visual predators, which involves chemical compounds responsible for pigmentation (van Der Veen, 2005).

The main objective of this study was to determine whether brook trout extinction directly affects both ephippium pigmentation and size in two lakes of LMNPC, while secondarily giving a preliminary assessment of the timing of brook trout extinction in these lakes, by using a paleolimnological approach. Cladoceran ephippia from sediment cores collected from two lakes in which brook trout populations went extinct were compared to those collected from two lakes with viable brook trout populations. The size and pigmentation of ephippia produced before the creation of LMNPC were compared in both types of lakes to those produced after its creation. Based on his- torical records, all four study lakes possessed viable brook trout populations during the first half of the $20^{\text {th }}$ century (i.e., before the creation of LMNPC), but intensive sampling conducted by Park Canada in the 1990's confirmed the presence of viable brook trout populations in only two of the lakes (Plante, 1996b). Therefore, although we only have approximate and uncertain information about the timing of brook trout extinction, we have a clear picture of the fish assemblage for the period following the creation of LMNPC.

This study was based on the analysis of both pigmentation and biometry of cladoceran ephippia deposited in the sediments during the 1950's and 1990's (based on ${ }^{210} \mathrm{~Pb}$ core dating). Two main hypotheses were tested concerning the expected patterns of planktivory between lakes that experienced brook trout extinction and lakes with viable brook trout populations. First, the ephippia produced in the 1990's should be smaller in lakes with brook trout than in those that experienced its extinction. Second, lakes with brook trout are expected to show lower levels of pigmentation in the ephippia produced in the 1990 's than those produced in the other lakes. These expected results should reflect the reduction of predatory pressure related to the extinction of brook trout. In contrast, no clear patterns are expected for the 1950's period for neither ephippium size nor pigmentation, since we hypothesized that brook trout were present in all of the study lakes at that time and went extinct only after the creation of LMNPC.

\section{METHODS}

\section{Study site}

The four study lakes (Alphonse, Genévrier, Giron and Noir, Tab. 1) are located in LMNPC, in the upper part of the Mauricie region $\left(46^{\circ} 46^{\prime} \mathrm{N}, 73^{\circ} 00^{\prime} \mathrm{W}\right.$, Québec, Canada). These are headwater lakes, located at an average elevation of $287 \mathrm{~m}$ asl, of relative small size (average of 12.2 hectares) and relatively shallow (average depth of 6.7 meters). LMNPC archives suggest that all lakes found on this territory were historically inhabited by brook trout (Lacasse and Magnan, 1994; Plante, 1996b). Lakes Alphonse and Giron still possess viable populations of brook trout that are currently exploited for sport fishing, whereas the brook trout populations of Lakes Genévrier and Noir are now extinct. Four introduced fish species (Tab. 1) are present in Lake Giron in addition to brook trout, and brook trout of Lake Alphonse are in sympatry with a cyprinid fish (Tab. 1). No other fish species are present in the two lakes where brook trout extinction has occurred, allowing the comparison of situations with complete absence of fish and situations with documented presence of fish (brook trout alone or accompanied by other 
planktivorous fishes). Lake Genévrier suffered a presumed extinction of its population in the 1980's, with the last brook trout catches by LMNPC staff in 1984 (Plante, 1996b; Masson et al., 2001). In Lake Noir, there is no documented historical proof of natural presence of brook trout, but the fishing club's archives indicate the lake was stocked with brook trout (at least) during the 1960's (Plante, 1996b).

\section{Sediment sampling and radioisotopic dating}

Short sediment cores were collected with an HTH gravity corer (Pylonex AB, Umeå, Sweden) at the deepest point of each lake during the ice-covered period in 2013. From each lake, duplicate sediment cores (approximately $30 \mathrm{~cm}$ length) were collected from one or two ice holes made within a $3 \mathrm{~m}^{2}$ area; one core was used for radioisotopic dating and the second for ephippia extraction and analysis. Intact sediment cores were transported to LMNPC laboratories (Saint-Mathieu or Saint-Jean-DesPiles, according to proximity with the sampled lake), where the cores were vertically extruded and sectioned into $1-\mathrm{cm}$ thick slices. The subsampled sections were placed into individual plastics bags and stored in the dark at $4^{\circ} \mathrm{C}$ until further manipulation.

We ensured the parallel cores retrieved from each lake represented replicates of the same stratigraphic intervals by comparing the profiles of organic content obtained by loss on ignition (LOI). To achieve this goal, $0.25 \mathrm{~g}$ of dried sediment $\left(100^{\circ} \mathrm{C}\right.$ overnight $)$ from each sediment layer were combusted for one hour at $550^{\circ} \mathrm{C}$. LOI manipulations were performed in two different laboratories, as one core was at the Institut National de la Recherche Scientifique, Centre Eau Terre Environnement for dating and the other was at Université du Québec à Trois-Rivières for ephippial analysis. Respectively, the top 16 and 12 sections of each core were analysed for organic matter, covering the period up to 1930. Some of the layers from the core located in Trois-Rivières could not be analyzed since ephippial analysis consumed the available sediment amount.

For sediment dating, core sections were freeze dried and analysed for gamma decay of radionuclides with an ORTEC HPGe Well Detector (Oak Ridge, TN, USA). The resulting data were used to determine sediment dates and mass accumulation rates by applying the constant rate of supply (CRS) model (Appleby and Oldfiel, 1983). Radionuclides analysed included ${ }^{210} \mathrm{~Pb}$ and ${ }^{226} \mathrm{Ra}$, which together allowed the determination of unsupported ${ }^{210} \mathrm{~Pb}$ $\left({ }^{226} \mathrm{Ra}\right.$ minus ${ }^{210} \mathrm{~Pb}$ ) and supported ${ }^{210} \mathrm{~Pb}$ (where ${ }^{226} \mathrm{Ra}$ and ${ }^{210} \mathrm{~Pb}$ are in equilibrium) for the CRS model. The artificially produced radionuclide ${ }^{137} \mathrm{Cs}$, which has an expected peak in the study area in 1963 in association with nuclear weapons testing, was also analysed, in order to validate the ${ }^{210} \mathrm{~Pb}$ chronology.

\section{Image analysis of ephippia}

Ephippia were manually isolated from sediments by examining the samples, with a dissecting scope. Thereafter, ephippia were rinsed with demineralised water into a $100 \mu \mathrm{m}$ sieve to eliminate residual particles. Both the 1950 's and 1990's layers for each of the four lakes were analysed for a total of eight samples, and an average of 20 ephippia were collected from each sample. Each ephippium was digitized with a stereomicroscope Nikon SMZ $745 \mathrm{~T}$ joined to a DS-L3 camera unit under a standardized $50 \mathrm{x}$ zoom. Even though pigmentation appeared symmetrical, the two sides of each ephippium were digitized in order to obtain an average of the data from both sides. Microscope settings were standardized and each picture had the same preset threshold level for white balance, with constant lighting. Biometric measures (length, width and total surface area of ephippia) were recorded with the DSL3 unit. Digital pictures were thereafter processed with GIMP 2.8.10 image manipulation software. Each ephippium image was extracted from its background in order to analyze only the pixels from the ephippium. Based on preliminary observations, two intensity colour thresholds have been selected for the pigmentation analysis (i.e., $75 / 255$ and $125 / 255$, Fig. 1). These thresholds are in relation with a colour intensity scale of 255 , in which 0 represents absolute black and 255 represents absolute white. The 75/255

Tab. 1. Main characteristics of the four study lakes, data measured in 1997 by the LMNPC (Michel Plante, LMNPC, unpublished results).

\begin{tabular}{|c|c|c|c|c|c|c|c|c|}
\hline & $\begin{array}{l}\text { Lake } \\
\text { area } \\
\text { (ha) }\end{array}$ & $\begin{array}{c}\text { Average } \\
\text { depth } \\
\text { (m) }\end{array}$ & $\begin{array}{l}\text { Cladoceran } \\
\text { (ind } \mathrm{L}^{-1} \text { ) }\end{array}$ & $\begin{array}{c}\text { Chlorophyll a } \\
\left(\mu \mathrm{g} \mathrm{L}^{-1}\right)\end{array}$ & $\begin{array}{c}\text { Brook } \\
\text { trout }\end{array}$ & $\begin{array}{c}\text { Fish } \\
\text { species } \\
\text { (n.) }\end{array}$ & $\begin{array}{l}\text { Introduced } \\
\text { species } \\
\text { (n.) }\end{array}$ & $\begin{array}{c}\text { DOC } \\
\left(\mathrm{mg} \mathrm{L}^{-1}\right)\end{array}$ \\
\hline Alphonse & 13.2 & 5.5 & 0.76 & 0.95 & Present & 2 & $1^{*}$ & 3.27 \\
\hline Genévrier & 4.0 & 8.0 & 0.72 & 1.17 & Extinct & 0 & 0 & 4.66 \\
\hline Giron & 28.3 & 8.6 & 2.33 & 1.14 & Present & 5 & $4^{* *}$ & 4.69 \\
\hline Noir & 3.4 & 4.6 & 48.60 & 1.59 & Extinct & 0 & 0 & 9.00 \\
\hline
\end{tabular}

DOC, dissolved organic carbon; *Allegheny pearl dace (Margariscus margarita); **Allegheny pearl dace, common shiner (Luxilus cornutus), northern redbelly dace (Chrosomus eos) and brown bullhead (Ameiurus nebulosus). Whereas the latter is mainly benthivorous, all the other introduced species are potentially planktivorous. 
threshold enables quantification of the percentage of darkened pixels in the ephippium picture (located between 0 and 75 on the colour intensity scale of 255), while the $125 / 255$ threshold provides the percentage of darkened and
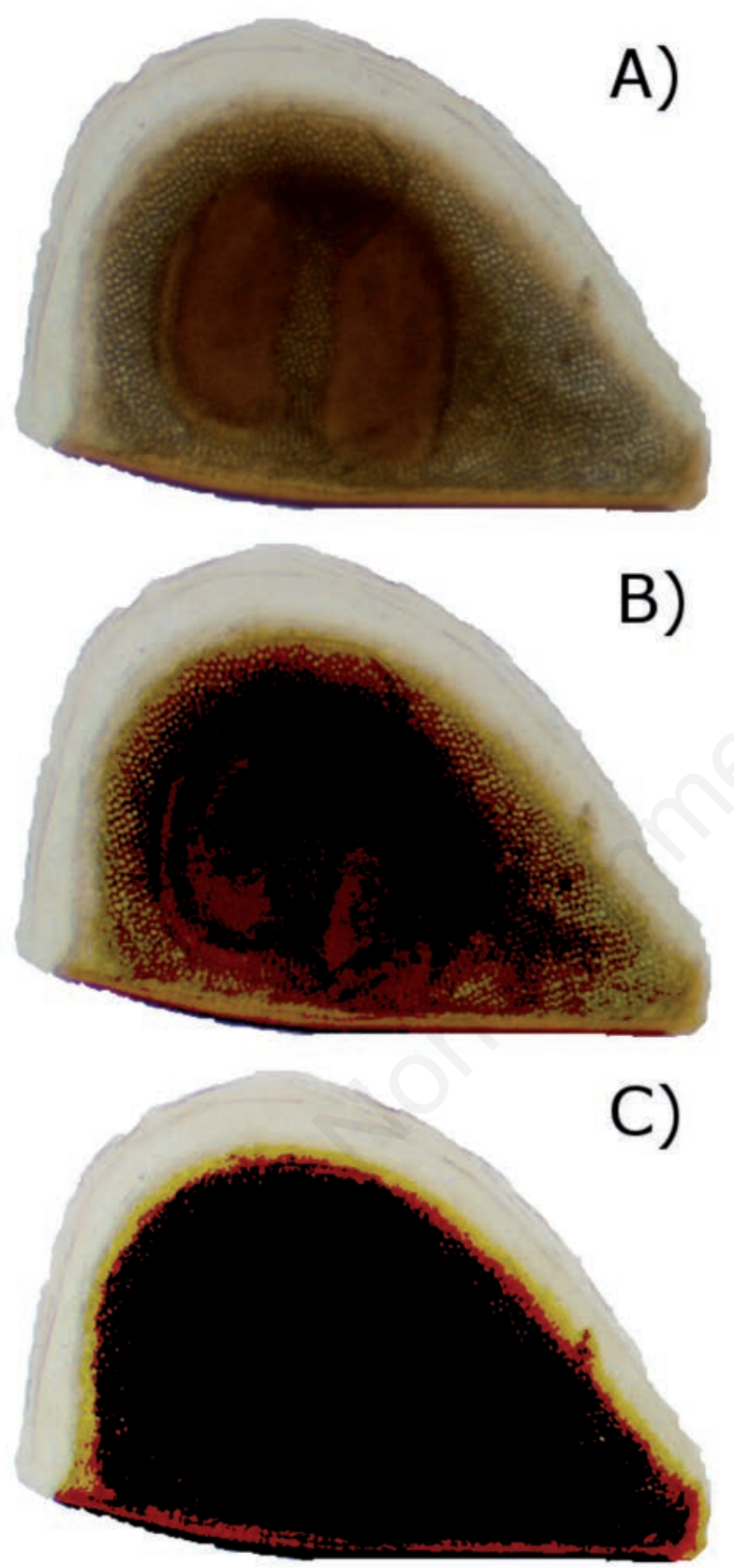

Fig. 1. Image analysis was used to find which percentage of the total pixels was darker than the threshold selected. A) Original picture. B) Picture processed with a threshold 75/255 and showing $34.5 \%$ dark pixels. C) Picture processed with a threshold $125 / 255$ and showing $64.4 \%$ dark pixels. moderately darkened pixels in the picture (located between 0 and 125 on the colour intensity scale of 255). Data registered represent the percentage of pixels from the selected image that are darker than the selected threshold (Gerrish and Caceres, 2003), and thus represent a proxy for the amount of melanin invested in the ephippium case. The selection of two different thresholds was motivated by the great range of variation in pigmentation among ephippia, where the variation in darker ephippia seemed better highlighted when using a threshold of 75 and that of the clearer ephippia by using a threshold of 125 (Gerrish and Caceres, 2003). We also used image analysis to extract measures of ephippia total area. Ephippia were sorted into morphotypes (M1, M2 and M3, Fig. 2) based on a visual examination of their characteristics, namely shape, the presence or absence of a spine, degree of symmetry, texture and length/width ratio. Size and pigmentation were not used to classify ephippia, but instead used as dependent variables in the analyses.

\section{Statistical analysis}

Analyses were conducted only on the M1 morphotype to get a clearer picture of the observed variations. In order to take into account the nested nature of our sampling design (several ephippia per sample with two strata sampled in each lake), we used a mixed modelling approach to analyse our data. This approach not only allowed us to model properly the correlation among non-independent observations, but also to explicitly model heterogeneous variance if needed. To build our models, we applied the approach suggested by Zuur et al. (2009) based on the comparison of the Akaike Information Criterion (AIC) among different models: i) we first selected the appropriate random term by comparing a full model fitted with all the independent fixed variables considered as important given the sampling design (lake type, stratum and their interaction), to an equivalent model with a random intercept for each study lake, and to another model with both a random intercept and slope for each study lake. Restricted Estimates Maximum Likelihood (REML) was used to calculate AIC in this case; ii) we then selected the appropriate fixed terms by comparing the fit of the full model to a model without the interaction term and to a model without the stratum term (lake type only). Maximum Likelihood (ML) was used to calculate AIC in this case; iii) once the random and the fixed terms were selected, the final model was refitted with REML to obtain a correct parameter estimation (Zuur et al., 2009). All the models were fitted by using the lme()function in the nlme package in R. Given that the preliminary exploration of the data suggested a problem of among-groups variance homogeneity, we included a heterogeneous variance term when needed by using the varIdent()function in the nlme package. Three dependent variables were modelled with this approach: 
ephippium surface (hereafter Surface), percent ephippium pigmentation at threshold 75/255 (hereafter Dark75) and 125/255 (hereafter Dark125). All statistical analyses were performed in R 3.3.0 (R Core Team 2016).

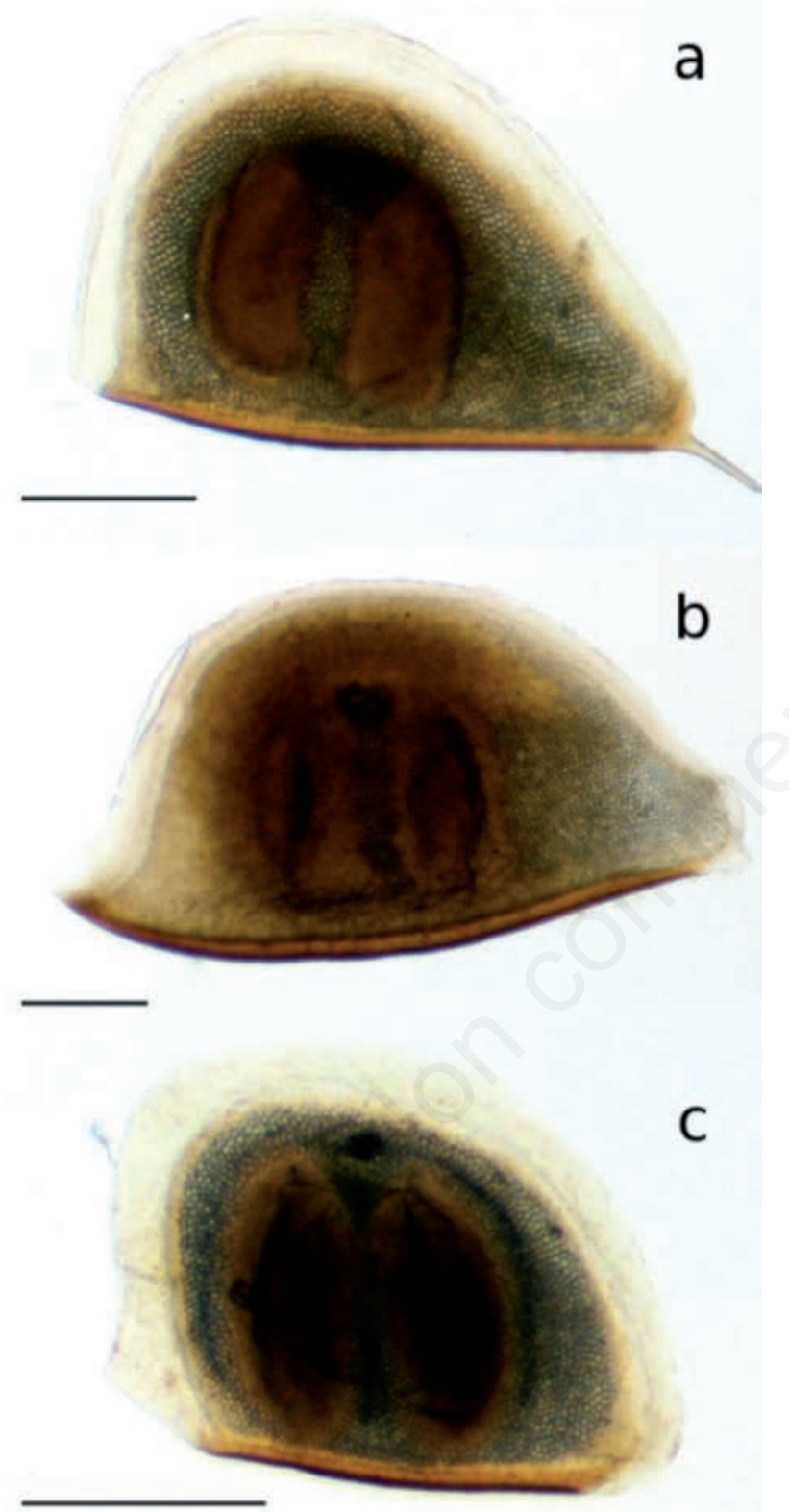

Fig. 2. The three visually identified morphotypes (M1-M3). a) M1 (corresponding to D. pulex): spine, asymmetric shape, medium-sized margins, average length:width ratio of 1.42. b) M2: spine (broken on the picture), flare shape on both sides, narrow margin and average length/width ratio of 1.69. c) M3: no spine, spherical shape, large margins and average length:width ratio of 1.29; note the different scale for each picture (a $250 \mu \mathrm{m}$ horizontal reference bar is presented on the bottom left of each specimen).

\section{RESULTS}

The comparison of LOI profiles for each lake strongly supports that duplicate cores have a similar stratigraphy (and also dates and mass sedimentation rates, Supplementary Fig. 1). For three lakes (Alphonse, Genévrier and Noir), the accurate placement of the ${ }^{137} \mathrm{Cs}$ peak validated the ${ }^{210} \mathrm{~Pb}$ dating. For Lake Giron, the peak for ${ }^{137} \mathrm{Cs}$ was later than expected (1990). Dating the cores allowed the selection in each of the studied lakes of the 1950 and 1990 sediments layers, which represent the periods before and after park creation (Supplementary Fig. 2 and Tab. 1).

M1 resulted as the most ubiquitous morphotype (81\% of analysed ephippia), being the only morphotype present in all of the study lakes, while M2 and M3 each accounted for $9 \%$ of the total ephippia and were found in one lake each. Ephippium morphotype M1 was identified as belonging to species of the Daphnia pulex Leydig, 1860 group, based on two morphological identification keys created by Vandekerkhove (2004) and Mergeay et al. (2005). Vandekerkhove's key also permitted us to presume that the M3 morphotype is related to Daphnia ambigua Scoufield, 1946 species. However, the two identification keys did not provide enough information to identify the M2 morphotype. Lakes with brook trout showed more diversity of morphotypes compared to fishless lakes, with Lake Alphonse containing both M1 and M2, and Giron lake containing both M1 and M3. Only the morphotype M1 was found in fishless lakes (Genévrier and Noir). Since M1 resulted as the most common ephippium morphotype in all the studied lakes, statistical analyses were conducted only on the M1 morphotype to get a clearer picture of the observed variations.

All selected models included a random intercept for the lake term and at least a term for heterogeneous variance: for both the Surface and Dark 75 variables we included a term for heterogeneous variance across lakes, whereas for the Dark125 variable, we also included a term for heterogeneous variance across strata. The visual representation by boxplots clearly illustrates this point (see the variables spread of boxplots among lakes in Figs. 3 and 4). In all cases, the model selection for the fixed term ended up with a model including only the "lake type" factor, suggesting that neither the stratum, nor its interaction with the lake type were strong predictors for the three modelled variables. For the variable Surface (Fig. 3), the results of the t-test showed that lake type is not significantly related to dependent variable $(\mathrm{P}=0.174$, Tab. 2). In contrast, for both Dark75 and Dark125 variables (Fig. 4), the results of the t-test showed that lake type is a significant predictor of the dependent variable $(\mathrm{P}=0.0238$ and 0.0351 respectively, Tab. 2), with darker ephippia found in fishless lakes and sediment layers. 


\section{DISCUSSION}

Our study clearly indicated that ephippium pigmentation may be a better indicator of the presence of fish predation than ephippium size, a trait that showed a less clear pattern of variation between lakes with and without fish in our study system. As predicted, we found a sharp difference in pigmentation (both Dark 75 and Dark125 variables) between ephippia collected from the 1990's sediment layers from lakes with or without fish. Ephippia collected from fishless lakes were significantly (both statistically, given the alpha level, and biologically, given the $\%$ variation between lake types) darker than ephippia from lakes with fish. Although we did not directly analyze the optical properties of individual ephippia (Nevalainen et al., 2016), the photographic approach used here (Gerrish and Cacéres, 2003) appeared to be sufficiently sensitive to track variations in ephippia pigmentation and to allow discriminating variations in fish predation pressure.

Small differences in size of ephippia between lake types were also detected, with ephippia showing a tendency to be larger in fishless lakes. Unexpectedly, the same general pattern was also observed for the 1950's period, suggesting that either brook trout extinction occurred before this period (e.g., at Lake Noir, for which no clear proof of brook trout presence is available for 1950), or

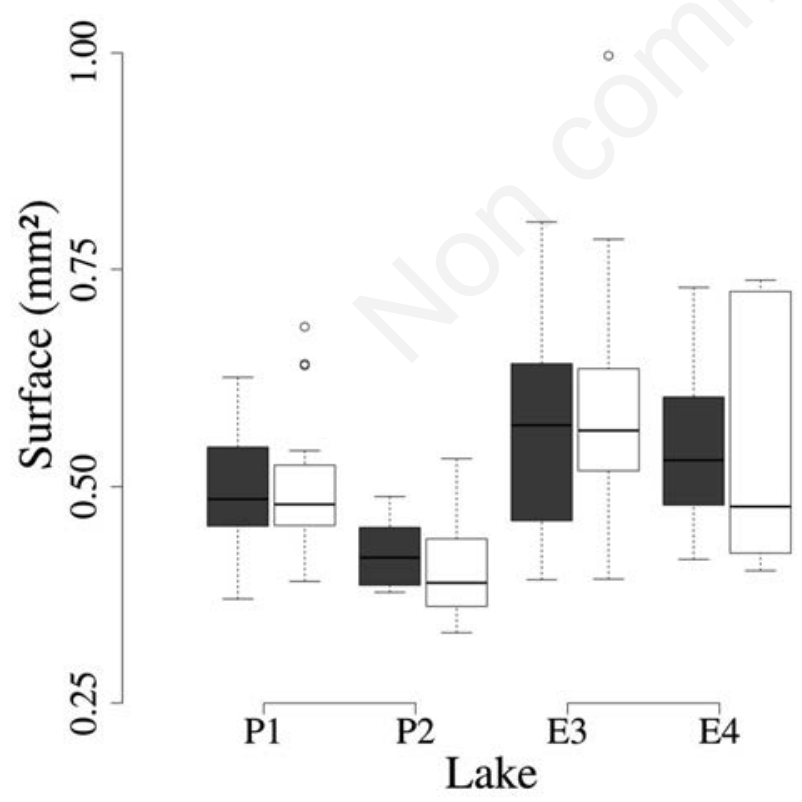

Fig. 3. Boxplot showing variations of ephippium surface according to lake and sediment layers (before and after park creation). Lakes P1 (Alphonse) and P2 (Giron) have viable brook trout populations whereas lakes E3 (Genévrier) and E4 (Noir) were fishless in the 1990's. Grey: period before park creation; white: period after park creation. that the population levels were already critically low before 1984 (e.g., at Lake Genévrier, when the last observation of brook trout is available), with resulting low predation pressure on zooplankton. The relatively small
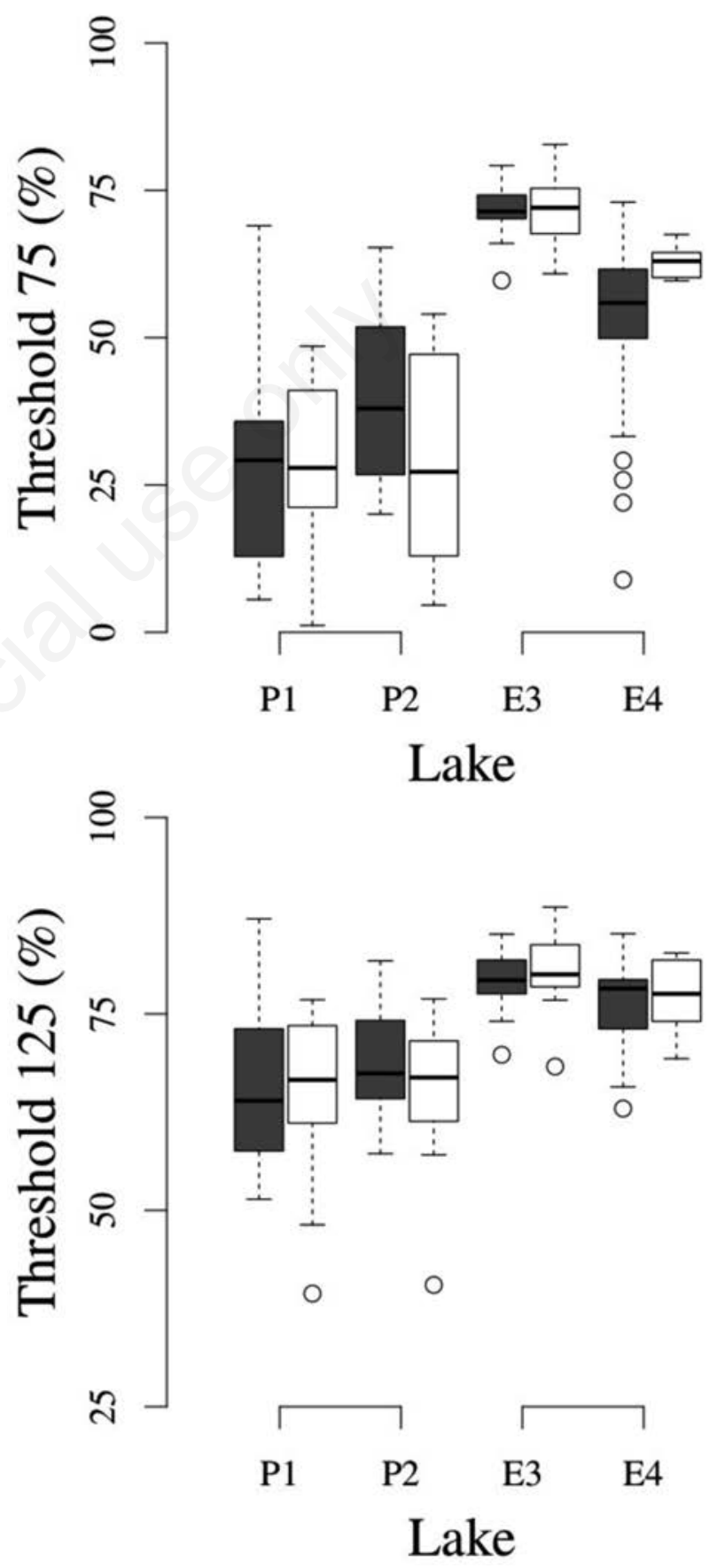

Fig. 4. Boxplots showing variations of the percentage of dark pixels at threshold 75 (panel a) and at threshold 125 (panel b) according to lake (viable or extinct) and sediment layer (before or after park creation). Grey: period before park creation; white: period after park creation. 
size of the two fishless lakes could be related not only to a greater physical instability of these systems, but also to small fish population size, which could increase the vulnerability to stochastic events that could lead to extinction (Dunham et al., 1999).

It has already been shown that visual predators, such as brook trout, operate a strong selection pressure on large-sized cladocerans (Brooks and Dodson, 1965; Galbraith, 1967), which in turn reduces of the average population body size (Hart and Bychek, 2011). Predation pressure could eventually lead to a reduction in size at first reproduction, either by clonal replacement, or by phenotypic plasticity (Latta et al., 2007), which could be mirrored by a reduction in average ephippium size. Jeppesen et al. (2002), for example, observed a relationship between actual fish abundance and ephippia dorsal length in surface sediment. Our data are in accordance with this hypothesis, with fishless lakes showing a tendency for larger ephippium size, compared to lakes with fish, which is related to adult body size. We also observed a high within-lake variability for this trait, which reduced the possibility to find significant differences given the low sample size of our study, and consequently, low power of our statistical analysis. Nevertheless, the observation of clear differences in ephippium pigmentation between lake types highlights the sensitivity of this trait to variations in fish predation pressure.

Low levels of body pigmentation in the presence of visual predators have been observed in cladocerans (Reinikainen, 2012), but to our knowledge this is the first study to show a similar phenomenon in ephippia. In fact, despite the great deal of variability in ephippium pigmentation among lakes (Gerrish and Cacéres, 2003), and the capability by visual predators of selectively removing individuals carrying darker ephippia (Mellors, 1975), the relationship between population ephippium pigmentation and fish predation has not been established previously. Since it has been shown that ephippium pigmentation is a strongly heritable trait (Gerrish and Cacéres, 2003), it is likely that the differences we observed between lake types are mainly due to clonal selection rather than plas- ticity per se.

Both selected measures of pigmentation (Dark75 and Dark125 variables) showed a significant relation to lake type. However, Dark 75 showed a clearer difference than Dark125 in pigmentation variation between lake types (Fig. 4). This finding suggests that lake type affected mainly the darkest range of pigmentation since Dark75 was more selective than Dark125 and integrated only the darkest pixels. This change might be related to an increased conspicuousness to visual predators when pigment concentration is higher (Zaret and Kerfoot, 1975). It was in fact observed that the quantity of pigmentation in the eyes of Ceriodaphnia cornuta Sars, 1885 is directly linked to predation risk, because its affects visibility (Zaret, 1972). Therefore, despite the high metabolic cost involved in melanin synthesis (Hebert and Emery, 1990), cladocerans produced darker ephippia in the absence of visual predators. This could be explained by the production of phenolic compounds associated to pigmentation, which can provide greater hardness and a better protection of the eggs to UV radiation, parasites and predation (Zaret, 1972; Hessen, 1996; Gerrish, 2001; Gerrish and Caceres, 2003). In addition, ephippium pigmentation increases resistance to digestion by numerous planktivorous fish, fish-eating birds and mammals (Mellors, 1975), which can provide cladocerans species a wider range of dispersal across a territory (Proctor, 1964; Proctor and Malone 1965; Mellors, 1975). Therefore, it seems logical that in lakes where visual predators are absent, ephippium pigmentation is relatively high in order to increase hardness and enhance protection against UV radiation, parasites and predators.

Nevertheless, it is necessary to consider that pigmentation levels may be possibly driven by other factors affecting the UV risk in lakes, such as changes in dissolved organic carbon (DOC) concentration (Cooke et al., 2015) or in solar activity (Nevalainen et al., 2016). In fact, variations in DOC concentration, and in particular in its coloured or chromophoric component (cDOM), can strongly control UV penetration in the water column,

Tab. 2. Results for the fixed terms of the selected mixed linear models concerning the three studied variables. Surface: ephippium total area expressed in pixels, Dark75: percentage of dark pixels at threshold 75/255, Dark125: percentage of dark pixels at threshold 125/255.

\begin{tabular}{llccccc} 
Variable & & Value & Std. Error & df & t-value & P-value \\
Surface & Intercept & $93,085.01$ & 5783.30 & 124 & 16.10 & $<0.001$ \\
& Lake type (viable) & $-16,669.05$ & 8038.32 & 2 & -2.07 & 0.1738 \\
Dark75 & Intercept & 66.98 & 3.80 & 124 & 17.61 & $<0.001$ \\
& Lake type (viable) & -36.48 & 5.74 & 2 & -6.36 & 0.0238 \\
\hline \multirow{2}{*}{ Dark125 } & Intercept & 78.18 & 1.47 & 24 & 52.99 & $<0.001$ \\
& Lake type (viable) & -12.15 & 2.34 & -5.19 & 0.0351 \\
\hline
\end{tabular}

df, degree of freedom. 
and can therefore potentially modulate pigmentation levels in cladocerans. Similarly, variations in solar activity have been shown to be related to modulate UV-risk in fishless arctic ponds and, in turn, variations in ephippia melanization (Nevalainen et al., 2016). However, in contrast to artic waters, which offer no strong protection against UV due to a lack of refugia, such as deep layers and shading macrophytes, our study lakes offer to zooplankton the possibility to avoid damaging UV radiation by changing their vertical or horizontal distribution during the day (Williamson et al. 2011). Thus, it is reasonable to suppose that ephippia pigmentation responded more strongly to fish predation than to variation in UVrisk in our systems. This might also explain why pigmentation levels tended to differ between our two fishless lakes, albeit the difference was clearly smaller than between fish and fishless lakes, with the brownwater Lake Noir (French for "black") showing lower levels of ephippial pigmentation than Lake Genévrier, which has lower DOC concentration. However, extrapolating actual DOC concentration to the past decades has obvious limitations and more explicit analyses of the relationship between UV-risk and ephippial pigmentation along a gradient of DOC concentration in natural lakes are necessary to elucidate this point.

AIC-based model selection did not support models including the time period or the interaction between the period and lake type, suggesting that ephippia produced before and after the creation of LMNPC have similar pigmentation levels in fishless lakes. However, a slight after $v s$ before increase in pigmentation was observed at least for Lake Noir, suggesting a change in predation pressure. Lake Noir was mainly stocked with brook trout in the 1960's, but there is no proof that populations were maintained in this lake until the park creation (Plante, 1996b). Even if they were present in the 1950's, brook trout populations in this lake may not have been abundant enough to impose strong predation pressure on cladoceran populations. In that case, ephippia would not show the strong changes after the extinction of the remaining predators. The lack of time effect might also be related to physicochemical water status of those lakes, such as water turbidity (Finlay et al., 2007), which can prevent efficient visual predation and thus hamper topdown effects on zooplankton (Finlay et al., 2007). However, it is also important to note that our sampling design did not allow us to compare fishless lakes with lakes with brook trout only, because of the presence of one to three additional species of planktivorous fish in brook trout lakes. Overall, this implies that the potential contrast between lake types is larger than between different time periods within lakes that experienced brook trout extinction.

\section{CONCLUSIONS}

Although this study did not show strong effects of lake types on average ephippium size, ephippium pigmentation was clearly correlated with the presence or absence of planktivorous fish in the 1990's. Our results also show that the level of planktivory in fishless lakes were very low in the 1950's, suggesting either the absence of brook trout or very low population abundance. Our study expanded the findings by Jeppesen and co-workers (2002) by showing that the degree of ephippium pigmentation can be used in addition to ephippium size as a tool to quickly assess fish density in lakes when only sediment samples are available. Complementary paleoecological analyses of other indicators of changes in the fish predation pressure (e.g., based on chaoborid mandibles, Uutala 1990) are planned in order to strengthen these preliminary results on the impact of fish extinction in our study lakes.

\section{ACKNOWLEDGMENTS}

We would like to thank Patricia Bolduc, Paméla Magnan-Baril, William Brassard, Freddy Gutierrez Trejo, Chantal Fournier, Dany Bouchard and Joëlle Guitard for their valuable help. We are greatly thankful to two anonymous reviewers for improving the first version of this work and to Michel Plante and his collaborators of LMNPC for their assistance with winter sampling and to Parks Canada for granting access to the study sites.

\section{REFERENCES}

Appelby PG, Oldfield F, 1983. The assessement of ${ }^{210} \mathrm{~Pb}$ data from sites with varying sediment accumulation rates. Hydrobiologia 103:29-35.

Bertolo A, Magnan P, Plante M, 2008. Liking the occurrence of brook trout with isolation and extinction in small Boreal Shield lakes. Freshwater Biol. 53:304-321.

Brooks JL, Dodson SI, 1965. Predation, body size, and composition of plankton. Science 150:28-35.

Cooke SL, Fisher JM, Kessler K, Williamson CE, Sanders RW, Morris DP, Porter JA, Jeffrey WH, DeVaul Princiotta S, Pakulskim JD, 2015. Direct and indirect effects of additions of chromophoric dissolved organic matter on zooplankton during large scale mesocom experiments in an oligotrophic lake. Freshwater Biol. 60:2362-2378.

Davidson TA, Bennion H, Jeppesen E, Clarke GH, Sayer CD, Morley D, Odgaard BV, Rasmussen P, Rawcliffe R, Salgado J, Simpson GL, Amsinck SL, 2011. The role of cladocerans in tracking long-terme change in shallow lake trophic status. Hydrobiologia 676:299-315.

Dunham J, Peaock MD, Tracy CR, Nielsen J, Vinyard G, 1999. Assessing extinction risk: integrating genetic information. Conserv. Ecol. 3:2.

Dzialowski AR, Lennon JT, O’Brien WJ, Smith VH, 2003. Pred- 
ator-induced phenotypic plasticity in the exotic cladoceran Daphnia lumholtzi. Freshwater Biol. 48:1593-1602.

Finlay K, Beisner BE, Patoine A, Pinel-Alloul B, 2007. Regional ecosystem variability drives the importance of bottom-up and top-down factors for zooplankton size spectra. Can. J. Fish. Aquat. Sci. 64:516-529.

Gerrish GA, 2001. Maintaining pigment variation in aquatic systems: the cause and consequences of pigment variation in Daphnia pulicaria ephippial egg casings. MS Thesis, University of Illinois at Urbana-Champaign, USA.

Gerrish GA, Cacéres CE, 2003. Genetic versus environmental influence on pigment variation in the ephippia of Daphnia pulicaria. Freshwater Biol. 48:1971-1982.

Hansson LA, 2004. Plasticity in pigmentation induced by conflicting threats from predation and UV radiation. Ecology 85:1005-1016.

Hebert PDN, Emery CJ, 1990. The adaptative significance of cuticular pigmentation in Daphnia. Funct. Ecol. 4:703-710.

Hessen DO, 1996. Competitive trade-off strategies in arctic Daphnia linked to melanism and UV-B stress. Polar Biol. 16:573-579.

Jeppesen E, Jensen JP, Amsinck S, Landkildehus F, Lauridsen T, Mitchell SF, 2002. Reconstructing the historical changes in Daphnia mean size and planktivorous fish abundance in lakes from the size of Daphnia ephippia in the sediment. J. Paleolimnol. 27:133-143.

Lacasse S, Magnan P, 1994. [Distribution Post-Glaciaire de l'Omble de fontaine dans le bassin hydrographique du fleuve Saint-Laurent: Impact des interventions humaines]. [Book in French]. Université du Québec à Trois-Rivières, pour le Ministère de l'Environnement et de la Faune du Québec, Trois-Rivières, QC, Canada: 83 pp.

Latta L, Bakelar JW, Knapp RA, Pfrender ME, 2007. Rapid evolution in response to introduced predators II. BMC Evol. Biol. 7:21.

Masson S, Pinel-Alloul B, East P, Magnan P, Hogue G, Barabé $A, 2001$. [Programme de surveillance des écosystèmes aquatiques du Parc National de la Mauricie].[in French]. Groupe de recherche en limnologie et environnement aquatique pour Parcs Canada, Services de conservation des écosystèmes, Parc National de la Mauricie, QC.

Mellors WK, 1975. Selective predation of ephippial Daphnia and the resistance of ephippial eggs to digestion. Ecology 56:974-980.

Mergeay J, Verschuren D, De Meester L, 2005. Daphnia species diversity in Kenya and a key to the identification of their ephippia. Hydrobiologia 542:261-274.
Nevelainen L, Rantala MV, Luoto TP, Ojala A, Rautio M, 2016. Long-term changes in pigmentation of arctic Daphnia provide potential for reconstructing aquatic UV exposure. Quaternary Sci. Rev. 144:44-50.

Plante M, 1996a. [Plan de conservation des écosystèmes aquatiques].[in French]. Parc National de la Mauricie, Parcs Canada, Service de conservation des ressources naturelles, Parc National de la Mauricie, QC.

Plante M, 1996b. [Les communautés de poisson du Parc National de la Mauricie, de l'origine à aujourd'hui].[in French]. Parcs Canada, Service de conservation des ressources naturelles, Parc National de la Mauricie, QC.

Proctor VW, 1964. Viability of crustacean eggs recovered from ducks. Ecology 45:656-658.

Proctor VW, Malone CR, 1965. Further evidence of the passive dispersal of small aquatic organisms via the intestinal tract of birds. Ecology 46:728-729.

R Core Team, 2016. R: A language and environment for statistical computing. R Fundation for Statistical Computing. Vienna, Austria. Available from: https://.R-project.org/

Reinikanen M, Ahlen E, 2012. Ressurected Ceriodaphnia quadrangula highlight differences between pheno- and genotypic expressions. Ecol. Evol. 2:2989-2998.

Utala AJ, 1990. Chaoborus (Diptera: Chaoboridae) mandibulespaleolimnological indicators of the historical status of fish populations in acid-sensitive lakes. J. Paleolimnol. 4:139-151.

van Der Veen IT, 2005. Costly carotenoids: a trade-off between predation and infection risk? J. Evol. Biol. 18:992-999.

Vandekerkhove J, Declerck S, Vanhove M, Brendonck L, Jeppesen E, Conde Porcuna JM, De Meester L, 2004. Use of ephippial morphology to assess richness of anomopods: potentials and pitfall. J. Limnol. 63:75-84.

Williamson CE, Fisher JM, Bollens SM, Overholt EP, Breckenridge JK, 2011. Toward a more comprehensive theory of zooplankton diel vertical migration: integrating ultraviolet radiation and water transparency into the biotic paradigm. Limnol. Oceanogr. 56:1603-1623.

Zaret MT, 1972. Invisible prey, and the nature of polymorphism in the Cladocera (Class Crustacea). Limnol. Oceanogr. 17:171-184.

Zaret MT, Kerfoot WC, 1975. Fish predation on Bosmina longirostris: body-size selection versus visibility selection. Ecology 56:232-237.

Zuur AF, Leno EN, Walker NJ, Saveliev A, Smith GM, 2009. Mixed effects models and extensions in ecology with R. Statistics. Springer, New York: 574 pp. 